\title{
Unequal Teeth Widths for Torque Ripple Reduction in Permanent Magnet Synchronous Machines With Fractional-Slot Non-Overlapping Windings
}

\author{
Ilya Petrov, Pavel Ponomarev, Yulia Alexandrova, Juha Pyrhönen, LUT
}

\begin{abstract}
Permanent magnet synchronous machines with fractional-slot non-overlapping windings (FSPMSM), also known as tooth-coil winding permanent magnet synchronous machines (TCW PMSM), have been under intensive research during the latest decade. There are many optimization routines explained and implemented in the literature in order to improve the characteristics of this machine type.

This paper introduces a new technique for torque ripple minimization in TCW PMSM. The source of torque harmonics is also described. The low order torque harmonics can be harmful for a variety of applications, such as direct drive wind generators, direct drive light vehicle electrical motors, and for some high precision servo applications.

The reduction of the torque ripple harmonics with the lowest orders $\left(6^{\text {th }}\right.$ and $\left.12^{\text {th }}\right)$ is realized by machine geometry optimization technique using finite element analysis (FEA). The presented optimization technique includes the stator geometry adjustment in TCW PMSMs with rotor surface permanent magnets and with rotor embedded permanent magnets. Influence of the permanent magnet skewing on the torque ripple reduction and cogging torque elimination was also investigated. It was implemented separately and together with the stator optimization technique. As a result, the reduction of some torque ripple harmonics was attained.
\end{abstract}

Index Terms-Permanent magnet machines, TCW PMSM, tooth-coil winding, fractional slot PMSM. torque ripple.

\section{INTRODUCTION}

More and more applications start using TCW PMSMs instead of conventional distributed rotating-field slot winding permanent magnet synchronous machines (DW PMSMs), due to their advantages which are in details described in the literature [1]-[9].

Due to an extensive research and investigation of TCW PMSMs, numerous advices and hints are presented in the literature regarding the design procedures for this type of electrical machines.

In [10] efficiency observation was done for TCW PMSMs with different slot/pole combinations by varying steel grades and permanent magnet thicknesses. It was shown that if a PMSM has a high electrical frequency, the steel grade has more significant influence on the electrical machine efficiency than the permanent magnet thickness. Also a procedure for analytical evaluation of the optimal permanent magnet thickness has been presented.

In [11] design optimizations of TCW PMSMs and of DW PMSMs was done by using computationally efficient FEA and differential evolution. It was shown that it is possible to reach relatively low torque ripple with TCW PMSMs compared to
DW PMSMs, which is especially important with low speed and high torque applications (e.g. direct drive wind turbines).

In [12] detailed guidelines are given for the design of electric machines. However, some corrections are needed (e.g. for synchronous inductance evaluation) if the given recommendations are implemented for design of TCW PMSMs [9].

In [13], [14] analytical approaches of the inductance evaluation were suggested for TCW PMSMs. It was shown that, in TCW PMSMs with rotor surface permanent magnets [14], as well as with rotor embedded permanent magnets [13], besides the air-gap leakage inductance, the slot leakage inductance and the tooth-tip leakage inductance have also a significant contribution to the total synchronous inductance. This can cause a difficulty for TCW PMSM designers, which try to reduce the armature reaction. In these articles recommendations for the selection of slot/pole number and stator geometry are given in order to reach the desirable synchronous inductance.

In [15] the performance of a TCW PMSM with different number of phase winding turns is compared. It was shown that the optimal solution design for a traction application can vary according to the desirable vehicle characteristics (maximum torque, constant power speed range, etc).

With optimized designs, TCW PMSMs can achieve relatively low torque ripple and cogging torque. However, in order to reduce acoustic noise and mechanical vibrations, which are an especial concern in some applications, development of new PMSM design optimizations (with reduced torque ripple) is still continuing. This can increase the range of possible applications for TCW PMSMs.

In [16] the torque ripple reduction was attained by increasing the number of winding layers in a stator slot of a TCW PMSM, and by the optimization of the rotor geometry with embedded magnets, or, more specifically, by selecting the barriers angles in the rotor, which gives the lowest torque ripple.

In [17] it was shown that it is possible to reduce the torque ripple in TCW PMSMs with rotor surface permanent magnets by elimination of some harmful permanent magnet flux density harmonics in the air gap, while other order flux density harmonics (e.g. $3^{\mathrm{d}}$ ) can be kept in the air gap, providing an increase of the total flux without torque quality degradation. A particular air gap flux density waveform was achieved by adjusting the permanent magnet shape.

In [18] torque ripple minimization was achieved by a proper skewing. It was proven that it is not advisable to fully eliminate 
the torque ripple by skewing, because in this case the skewing pitch (angle) should be very large, which is not practical regarding to the average torque. In [18] the cogging torque and electromagnetic torque ripple harmonic components of the analyzed machine (DW PMSM) have the same harmonic order (i.e. $6^{\text {th }}$ ). Therefore, by eliminating the cogging torque, the torque ripple was also reduced. However, in TCW PMSMs the cogging torque can be of higher order compared to the electromagnetic torque ripple. For example, in 12-slot 10-pole PMSMs the main component of the cogging torque is $12^{\text {th }}$ order harmonic, whereas the largest torque ripple component is $6^{\text {th }}$ order harmonic. Therefore, as it is shown hereafter, it can be problematic to eliminate or even reduce $6^{\text {th }}$ torque ripple harmonic at the nominal load by implementing only skewing approach in TCW PMSMs.

In [19] behaviour of d- and q-axes inductances of a TCW PMSM with embedded magnets has been studied. It was shown that the inductance variation at different rotor positions has a direct influence on the torque ripple. In order to eliminate the torque ripple, it was suggested to include this inductance variation in the machine control algorithm, whereas the technique, described in this paper, reduces the inductance variation in a PMSM at the nominal load by a machine design approach.

Summarizing the results found in the literature which deal with the torque ripple reduction, it can be assumed that at the nominal load, torque ripple appears due to two main reasons: non-ideal sinusoidal waveform of the back EMF or phase current, and synchronous inductance variation.

This article studies the appearances of asymmetric local saturations in TCW PMSMs, due to the interaction of the permanent magnet flux and the armature winding flux in the stator side (in PMSM with rotor surface permanent magnets and with rotor embedded permanent magnets). The influence of these local saturations on the torque ripple at different load conditions is investigated and compared with the torque ripple impact by the interaction of the back EMF with the phase current. Also, a skewing technique for elimination of the main cogging torque harmonic component is proposed for a 12slot 10 pole PMSM. Thus, both of the most harmful torque ripple harmonics $6^{\text {th }}$ and $12^{\text {th }}$ can be significantly reduced or even eliminated ( $6^{\text {th }}$ harmonic by the method proposed in the article, and $12^{\text {th }}$ by skewing).

The novelty of this article is the consideration of the permanent magnet flux interaction with the armature reaction as a source of the local saturation which causes inductance variation as well as a significant magnetic coenergy variation. This phenomenon can increase the torque ripple in PMSMs. The aim of the paper is to describe the possibilities of the elimination of these effects. It should be noted that all dimensions were kept the same except those which were explicitly altered and described in the text, which means that the slot area and the current density were not changed. The optimization was realized using commercial software package.

Section II investigates the factors which cause local saturations in TCW PMSM at the stator side. Section III shows the influence of these local saturations on the torque ripple generation. It also proposes some solutions, in order to reduce the local saturation in the stator teeth. The described method was compared with the skewing of the machine, which is conventional method of torque ripple and cogging torque reduction. The skewing was implemented alone without any additional changes in machine geometry, and together with the method described in this paper. Possible disadvantages of the investigated methods and trade offs, which should be taken into account, are described in the paper.

\section{FACTORS OF LOCAL SATURATIONS IN TCW PMSMS AT THE STATOR SIDE}

Usually, during geometry optimization of a TCW PMSM it is assumed that at any load condition the peak flux densities in each stator tooth are the same [10], [11], [14]. Therefore, all stator teeth in TCW PMSM have the same width. The only exceptions are TCW PMSMs with an armature winding, the current linkage of which creates the magnetic flux, where one stator tooth has twice as high as armature flux compared to the adjacent tooth (e.g. single layer 12-slot 10-pole TCW PMSMs) [20]. In this case it is advisable to make unequal stator teeth in order to increase the total magnetic flux through the winding. However, it is not the case of double or multilayer windings, where the armature current linkage alone (without permanent magnets) creates the magnetic flux with the same peak values in each stator tooth with a 3-phase symmetrical winding system and alternating current. However, due to the presence of permanent magnets in TCW PMSMs, which interact with the armature winding flux, the peak flux density in adjacent stator teeth can differ from each other at loaded conditions, as is shown hereafter.

If it is assumed that the steel used in the magnetic circuit has a linear $B-H$ curve, and the stator teeth fluxes caused by the permanent magnets and caused by stator current linkage are sinusoidal, the total fluxes in two adjacent stator teeth $\Phi_{\text {tot.Tooth1 }}$ and $\Phi_{\text {tot.Tooth2 }}$ can be estimated by

$$
\begin{aligned}
\Phi_{\text {tot.Tooth1 }}= & \hat{\Phi}_{\text {PM.Tooth1 }} \sin \left(\omega t+\varphi_{1}\right) \\
& +\hat{\Phi}_{\mathrm{W} . \text { Tooth1 }} \sin \left(\omega t+\varphi_{2}\right), \\
\Phi_{\text {tot.Tooth2 }}= & \hat{\Phi}_{\text {PM.Tooth2 }} \sin \left(\omega t+\varphi_{3}\right) \\
& +\hat{\Phi}_{\mathrm{W} . \text { Tooth2 }} \sin \left(\omega t+\varphi_{4}\right),
\end{aligned}
$$

where $\Phi_{\mathrm{PM}}$. Tooth1 and $\Phi_{\mathrm{PM}}$. Tooth2 are the fluxes created only by the permanent magnets, $\Phi_{\mathrm{W}}$.Tooth1 and $\Phi_{\mathrm{W}}$.Tooth2 are the fluxes created only by the armature current linkage, $\varphi_{1}$ and $\varphi_{3}$ are the phase shifts of the fluxes created only by the permanent magnets, $\varphi_{2}$ and $\varphi_{4}$ are the phase shifts of the fluxes created only by the armature current linkage, $\omega$ is the electrical angular frequency. Variables in (1) and (2) are related to the first tooth (Tooth 1) and to the second tooth (Tooth 2) respectively.

In 12-slot 10-pole PMSMs with rotor surface permanent magnets (at $I_{\mathrm{d}}=0$ control), if the phase shift of the flux created by the armature current linkage in Tooth 1 is assumed 
a)

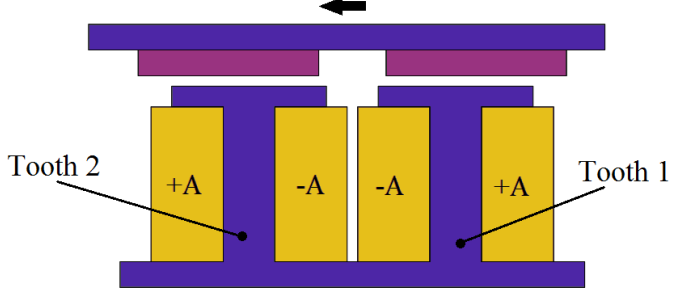

b)

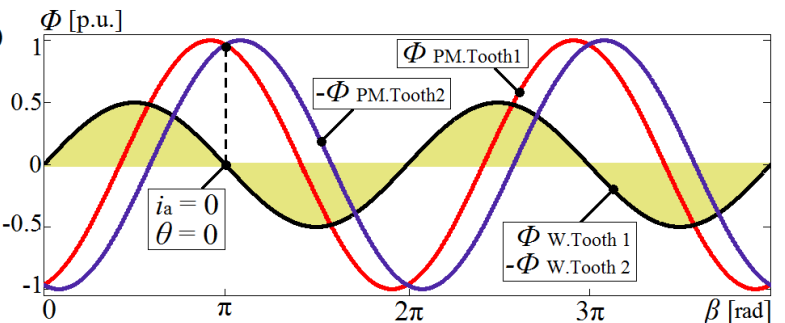

c)

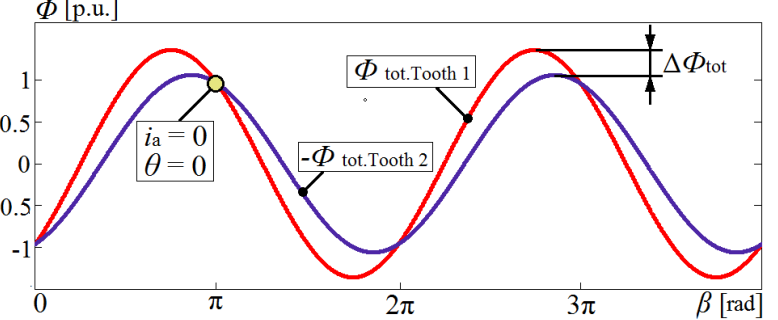

Fig. 1. Factors which lead to unbalanced peak flux densities in the stator teeth in TCW PMSM with $q=0.4$; a) Two adjacent stator teeth of one phase b) Fluxes in these teeth caused by permanent magnets (peak flux is 1 p.u.) and caused by the armature winding (peak flux is 0.5 p.u.); c) The resultant flux in the teeth. Saturation is not taken into account. It is assumed that stator teeth fluxes caused by the permanent magnets and caused by the stator current linkage are sinusoidal, $\beta$ is the electrical rotation angle, $\theta$ is the stator current linkage.

to be $\varphi_{2}=0^{\circ}$, then the phase shift of the flux created by the armature current linkage in Tooth 2 is $\varphi_{4}=180^{\circ}$, because it is created by the same current linkage, but with opposite polarity for different teeth. In this case, the phase shifts of the fluxes created by the permanent magnets are $\varphi_{1}=75^{\circ}$ and $\varphi_{3}=105^{\circ}$ in Tooth 1 and in Tooth 2 respectively. This means that the total fluxes $\Phi_{\text {tot.Tooth1 }}$ and $\Phi_{\text {tot.Tooth2 }}$ should have different peak values, as it is shown in Fig. 1.

In Fig. 1 (b) it can be seen that, the values of the fluxes in the stator teeth created by the permanent magnets alone $\left(\Phi_{\mathrm{PM} \text {.Tooth1 }}\right.$ and $\left.-\Phi_{\mathrm{PM} \text {.Tooth2 }}\right)$ have the same peaks. However, it is seen that the fluxes created by the armature winding $\left(\Phi_{\mathrm{W} . T o o t h 1}\right.$ and $-\Phi_{\mathrm{W}}$.Tooth2 $)$ increases the total flux in Tooth 1 more intensively than in Tooth 2 . The resultant total flux in Tooth $1\left(\Phi_{\text {tot.Tooth1 }}\right)$ and in Tooth $2\left(\Phi_{\text {tot.Tooth2 }}\right)$ are illustrated in Fig. 1 (c). It should be noted that it is true for TCW PMSMs with rotor surface permanent magnets and at maximum torque per ampere (MTPA) control, or in other words, at $I_{\mathrm{d}}=0$.

Fig. 1 illustrates the case, when the flux value produced by the current linkage is half of the flux value produced by the permanent magnets. However, electrical machines with different synchronous inductance values have different armature reactions, which affects the phenomenon described above. Fig.

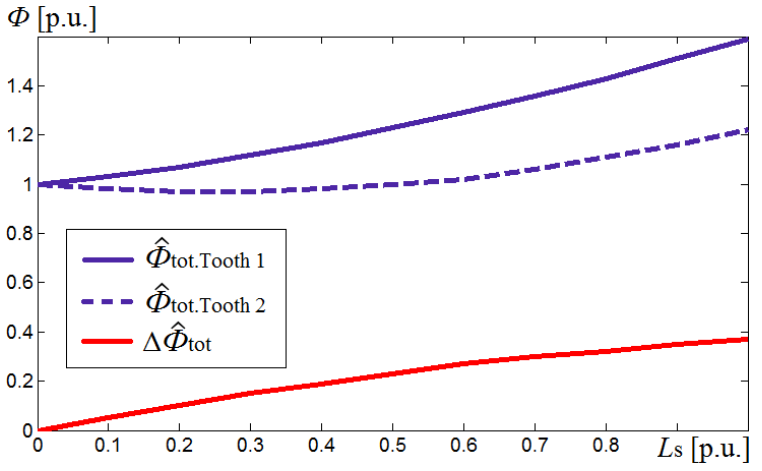

Fig. 2. Flux variations in adjacent stator teeth as function of the synchronous

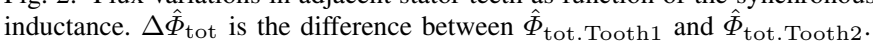

2 shows the fluxes variations in two adjacent stator teeth as a function of the synchronous inductance in a 12-slot 10pole PMSM. It is assumed that the stator steel has linear permeability, and the teeth fluxes, caused by the permanent magnets, has a sinusoidal waveform.

According to Fig. 2 the higher the synchronous inductance is, the larger the difference between the fluxes in the adjacent stator teeth will be. If the stator teeth widths are the same, it can lead to a significant peak flux density difference in the adjacent teeth, and, as a result, one stator tooth can be subjected to a stronger saturation effect than the neighbouring teeth of the same phase.

After the analysis of the phenomenon shown in Fig. 2, it can be concluded that the flux variation due to the armature current linkage, mostly takes place in one stator tooth (Tooth 1), whereas in the adjacent tooth (Tooth 2) the flux starts increasing only if the PMSM has a high synchronous inductance $\left(I_{\mathrm{d}}=0\right)$.

In addition to the electromagnetic torque, caused by the saturation variation, the cogging torque also has a significant influence on the overall torque ripple [18]. The common approach used to eliminate the cogging torque is skewing. However, skewing reduces the average torque by the skewing factor [12]. Therefore, the skewing angle should be as small as possible. In case of a 12-slot 10-pole machine, the main harmonic component of the cogging torque is $12^{\text {th }}$. In order to eliminate this harmonic component in radial flux PMSMs, the permanent magnets can be divided on two parts in the axial direction and shifted by 15 electrical degrees, Fig. 3 (b), whereas if the $6^{\text {th }}$ torque ripple should be reduced, the permanent magnets can be divided on two parts in the axial direction and shifted by 30 electrical degrees, Fig. 3 (c). However, as it is shown in [18], even if the permanent magnets are divided into two parts in the axial direction and shifted by 30 electrical degrees, in some working points, the $6^{\text {th }}$ harmonic of the torque ripple does not reduce significantly, but it can even increase at high loads.

\section{TORQUE RIPPLE REDUCTION METHODS}

Usually, the stator in a PMSM is made of laminated steel with high magnetic permeability. However, this material has 


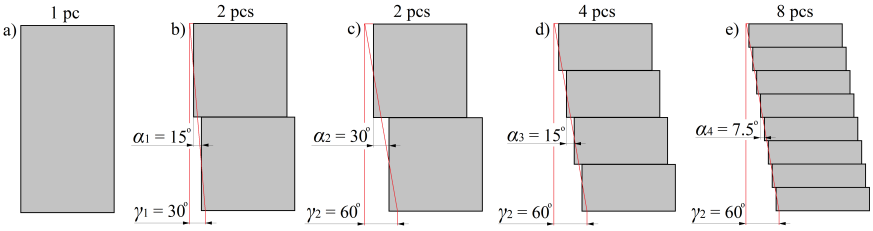

Fig. 3. a) Non-skewed magnet, b) Magnet skewing for the elimination of the $12^{\text {th }}$ order harmonic of the cogging torque, c) magnet skewing for the elimination of the $6^{\text {th }}$ order harmonic of the cogging torque, d) magnet skewing for the elimination of the $6^{\text {th }}$ and $12^{\text {th }}$ order harmonic of the cogging torque, e) magnet skewing for the elimination of the $6^{\text {th }}, 12^{\text {th }}$ and $24^{\text {th }}$ order harmonic of the cogging torque. $\gamma$ is the total skewing angle (if skewing is assumed to be continuous), $\alpha$ is the skewing angle pitch.

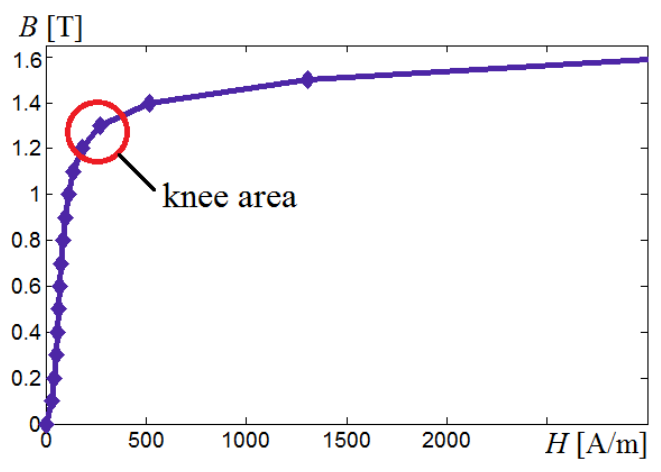

Fig. 4. $B-H$ curve of M400-50A steel grade [21].

non-linear $B-H$ curve, which represents the permeability reduction at higher flux density values in the steel. An example of a steel material $B-H$ curve used in electrical machines is shown in Fig. 4.

In Fig. 4 it can be seen that the $B-H$ curve of the steel has a so called knee point, where the permeability of the steel rapidly reduces at a particular flux density level.

Often, the electrical machines are designed in a way that the maximum value of the flux density in the steel is in the knee area, shown in Fig. 4, or just below it, in order to efficiently use the materials, and at the same time to keep the power density as high as possible [12]. This means that the peak flux density in the stator lamination is, usually, selected so that at higher flux density values the permeability of the steel is significantly reduced, which decreases the synchronous inductance of the PMSM.

In [19] it was shown that the synchronous inductance variation in TCW PMSMs causes torque ripple, and that its harmonic order determines the harmonic order of the torque ripple. From this information it can be concluded that it is preferable to keep the synchronous inductance constant, or to eliminate low order harmonics of the synchronous inductance variation, because high order harmonics of the torque ripple are less harmful compared to the low order harmonics [22].

As it is described in Section II, in TCW PMSMs with rotor surface permanent magnets, the flux density peaks in the adjacent stator teeth can have different values, which leads to different teeth permeability and, as a consequence, to the synchronous inductance variation. This phenomenon can cause

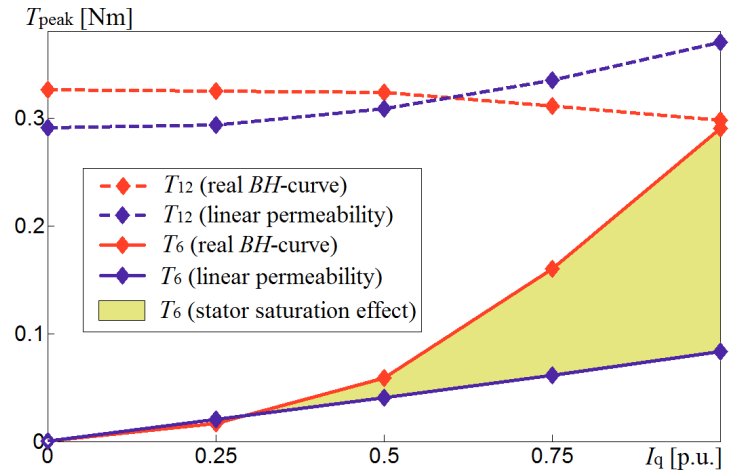

Fig. 5. $12^{\text {th }}$ and $6^{\text {th }}$ torque ripple harmonics of the machine with linear permeability and with the real $B H$-curve at the nominal load. Additional torque ripple which appears due to the saturation in the stator teeth is highlighted.
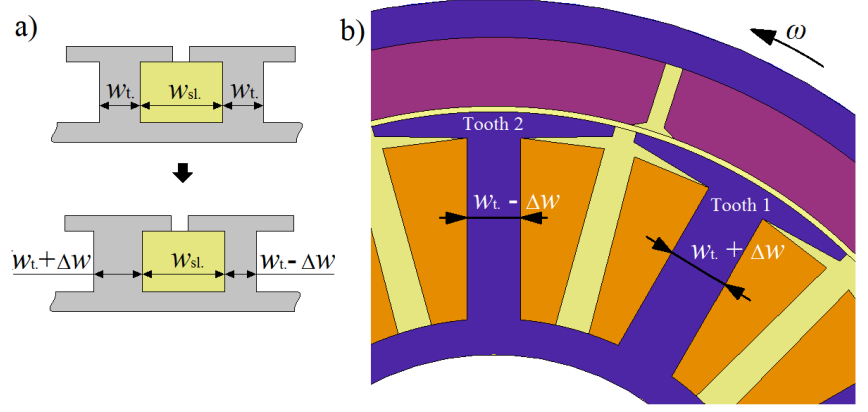

Fig. 6. Stator geometry optimization of a 12-slot 10-pole TCW PMSM for the torque ripple reduction at the nominal load, a) principle of the stator teeth width adjustment, b) resultant geometry of the TCW PMSM. $w_{\mathrm{t}}$. is the teeth width of the original machine, $w_{\mathrm{s} l}$. is the width of the slot (which is kept unchanged during the optimization), $\Delta w$ is the added (subtracted) width value, in order to adjust the flux density in stator teeth.

torque ripple in the PMSMs. However, in order to segregate the contributions of iron saturation and the non-ideal sinusoidal waveform of the back EMF to the torque ripple, 2D FEM analysis of two similar PMSMs described in [8] and shown in Fig. 6 (but with equal teeth widths) was prepared, so that the first PMSM has linear permeability, whereas the second one has the $B H$-curve of the real steel (M400-50A). The $6^{\text {th }}$ and $12^{\text {th }}$ harmonic components of the torque ripples of both PMSMs are shown in Fig. 5.

In Fig. 5 it can be seen that in the machine with the real $B H$-curve, the $6^{\text {th }}$ torque ripple harmonic increases rapidly at higher loads. Therefore, it can be concluded that the saturation effect in the stator side can indeed have a significant impact on the total torque ripple. However, other high order harmonics remained approximately at the same level and were not affected by different steel properties (except slightly different cogging torque). Therefore, mainly the $6^{\text {th }}$ torque ripple harmonic is affected, because the oversaturation in the phase occurs two times per electrical period, Fig. 1. The machine has 3 phases, which means that the affected torque ripple harmonic is $2 \times 3=6$.

It should be noted that no changes were made to tune 


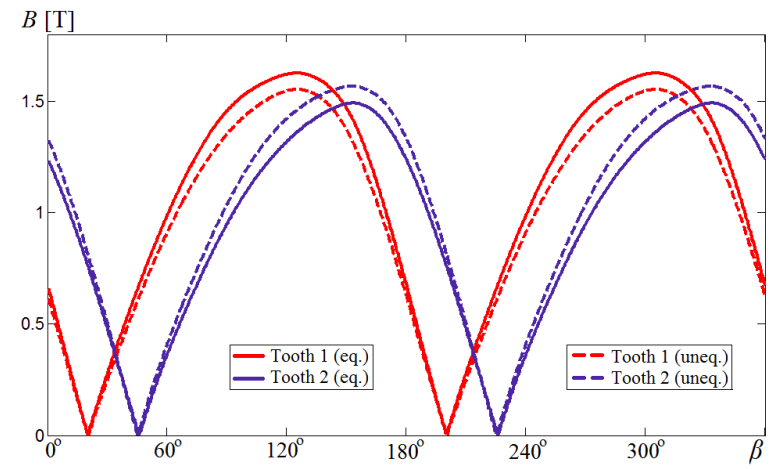

Fig. 7. Flux densities in the stator teeth of the original 12-slot 10-pole PMSM (with equal teeth widths) and of the redesigned PMSM (with unequal teeth widths) at the nominal load.
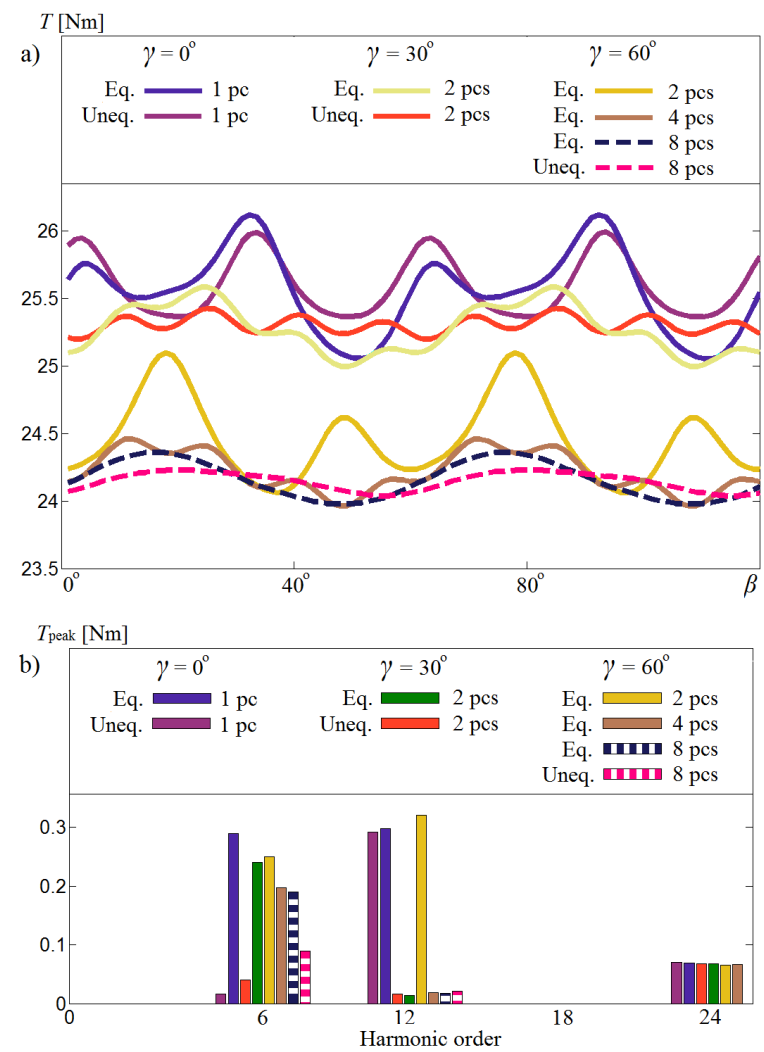

Fig. 8. a) Torque curves of the skewed and non-skewed original 12-slot 10pole PMSM (with equal teeth widths) and of the redesigned PMSM (with unequal teeth widths) at the nominal load and b) spectrum analysis of the torque curves.

the air gap flux density by permanent magnets, during the optimization process, but only the stator geometry adjustment is considered. This means that if the $6^{\text {th }}$ torque ripple should be eliminated, the torque ripple by saturation effect can be adjusted to compensate the torque ripple by the non-ideal sinusoidal waveform of the back EMF.

If the widths of the adjacent stator teeth are redesigned in a way that they have approximately the same peak flux density, it is possible to reduce or even fully eliminate some harmful
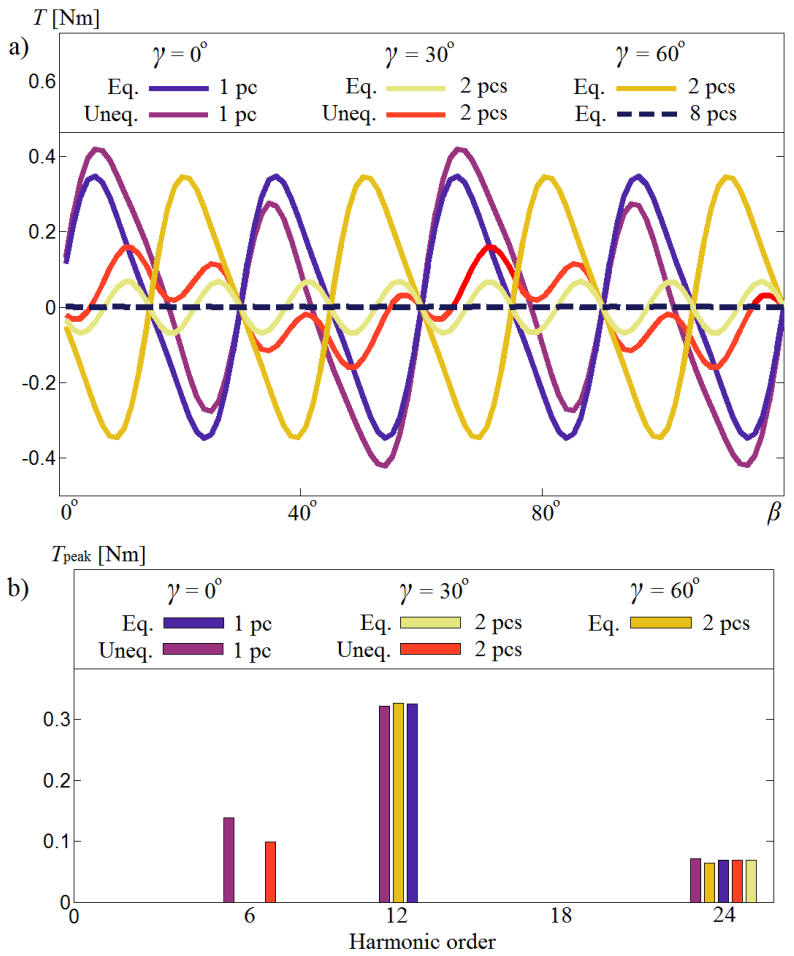

Fig. 9. a) Cogging torque curves of the skewed and non-skewed original 12slot 10-pole PMSM (with equal teeth widths) and of the redesigned PMSM (with unequal teeth widths) at no-load and b) spectrum analysis of the torque curves.

harmonics of the torque ripple. Three different TCW PMSMs were analyzed by using FEM - 12-slots 10-poles PMSM with outer rotor and surface permanent magnets [8], 144-slots 120poles PMSM with inner rotor and rotor surface permanent magnets [23], and 18-slots 16-poles with inner rotor and rotor embedded permanent magnets [9], [24].

The outer rotor 12-slot 10-pole PMSM was originally designed for a blower application [8]. This type of an application requires silent work, which together with tuning of the radial force (reduction of the radial force strength and elimination of its low order harmonic components) [25], also demands a low torque ripple. The geometry optimization of the stator is shown in Fig. 6. The widths of the stator teeth were changed that at the nominal load they have approximately the same flux density peaks as it is shown in Fig. 7. It should be noted that the width of one stator tooth was increased to the same extent as the width of the second tooth was decreased, or in other words the slot width (area) remained unchanged. Also, skewing is implemented in the same way as it is shown in Fig. 3, which in theory should eliminate or reduce the $6^{\text {th }}$, the $12^{\text {th }}$ and the $24^{\text {th }}$ harmonic components in the cogging torque and torque ripple.

The torque curves at the nominal load of the original motor and of the redesigned motor with and without skewing are illustrated in Fig. 8 with the spectrum analysis. For simplification purposes each design solution is marked as $(\gamma=$ skewing angle, Uneq. or Eq., number of pcs), where " $\gamma$ " shows the 
skewing angle (if skewing is assumed continuous), "Uneq. or Eq." determines if the stator teeth have unequal or equal widths, and "number of pcs" shows how many divisions the permanent magnets have along the axial direction.

TABLE I

VALUES OF THE HARMONIC COMPONENTS OF THE TORQUE CURVES ILLUSTRATED IN FIGS. 8, 9

\begin{tabular}{|c|c|c|c|}
\hline Geometry type & Harmonic order & No-load & Nominal load \\
\hline$\left(\gamma=0^{\circ}\right)$ Eq. $1 \mathrm{pc}$ & $T_{0}[\mathrm{Nm}]$ & 0 & 25.5 \\
\hline$\left(\gamma=0^{\circ}\right)$ Uneq. $1 \mathrm{pc}$ & $T_{0}[\mathrm{Nm}]$ & 0 & 25.6 \\
\hline$\left(\gamma=30^{\circ}\right)$ Eq. 2 pcs & $T_{0}[\mathrm{Nm}]$ & 0 & 25.3 \\
\hline$\left(\gamma=30^{\circ}\right)$ Uneq. 2 pcs & $T_{0}[\mathrm{Nm}]$ & 0 & 25.3 \\
\hline$\left(\gamma=60^{\circ}\right)$ Eq. 2 pcs & $T_{0}[\mathrm{Nm}]$ & 0 & 24.5 \\
\hline$\left(\gamma=60^{\circ}\right)$ Eq. 4 pcs & $T_{0}[\mathrm{Nm}]$ & 0 & 24.2 \\
\hline$\left(\gamma=60^{\circ}\right)$ Eq. 8 pcs & $T_{0}[\mathrm{Nm}]$ & 0 & 24.2 \\
\hline$\left(\gamma=60^{\circ}\right)$ Uneq. 8 pcs & $T_{0}[\mathrm{Nm}]$ & 0 & 24.2 \\
\hline$\left(\gamma=0^{\circ}\right)$ Eq. $1 \mathrm{pc}$ & $T_{6}[\mathrm{Nm}]$ & 0 & 0.29 \\
\hline$\left(\gamma=0^{\circ}\right)$ Uneq. $1 \mathrm{pc}$ & $T_{6}[\mathrm{Nm}]$ & 0.14 & 0.02 \\
\hline$\left(\gamma=30^{\circ}\right)$ Eq. 2 pcs & $T_{6}[\mathrm{Nm}]$ & 0 & 0.24 \\
\hline$\left(\gamma=30^{\circ}\right)$ Uneq. 2 pcs & $T_{6}[\mathrm{Nm}]$ & 0.1 & 0.04 \\
\hline$\left(\gamma=60^{\circ}\right)$ Eq. 2 pcs & $T_{6}[\mathrm{Nm}]$ & 0 & 0.25 \\
\hline$\left(\gamma=60^{\circ}\right)$ Eq. 4 pcs & $T_{6}[\mathrm{Nm}]$ & 0 & 0.2 \\
\hline$\left(\gamma=60^{\circ}\right)$ Eq. 8 pcs & $T_{6}[\mathrm{Nm}]$ & 0 & 0.19 \\
\hline$\left(\gamma=60^{\circ}\right)$ Uneq. 8 pcs & $T_{6}[\mathrm{Nm}]$ & 0 & 0.09 \\
\hline$\left(\gamma=0^{\circ}\right)$ Eq. $1 \mathrm{pc}$ & $T_{12}[\mathrm{Nm}]$ & 0.33 & 0.3 \\
\hline$\left(\gamma=0^{\circ}\right)$ Uneq. 1 pc & $T_{12}[\mathrm{Nm}]$ & 0.23 & 0.29 \\
\hline$\left(\gamma=30^{\circ}\right)$ Eq. 2 pcs & $T_{12}[\mathrm{Nm}]$ & 0 & 0.01 \\
\hline$\left(\gamma=30^{\circ}\right)$ Uneq. 2 pcs & $T_{12}[\mathrm{Nm}]$ & 0 & 0.02 \\
\hline$\left(\gamma=60^{\circ}\right)$ Eq. 2 pcs & $T_{12}[\mathrm{Nm}]$ & 0.33 & 0.32 \\
\hline$\left(\gamma=60^{\circ}\right)$ Eq. 4 pcs & $T_{12}[\mathrm{Nm}]$ & 0 & 0.02 \\
\hline$\left(\gamma=60^{\circ}\right)$ Eq. 8 pcs & $T_{12}[\mathrm{Nm}]$ & 0 & 0.02 \\
\hline$\left(\gamma=06^{\circ}\right)$ Uneq. 8 pcs & $T_{12}[\mathrm{Nm}]$ & 0 & 0.02 \\
\hline$\left(\gamma=0^{\circ}\right)$ Eq. $1 \mathrm{pc}$ & $T_{24}[\mathrm{Nm}]$ & 0.07 & 0.07 \\
\hline$\left(\gamma=0^{\circ}\right)$ Uneq. $1 \mathrm{pc}$ & $T_{24}[\mathrm{Nm}]$ & 0.07 & 0.07 \\
\hline$\left(\gamma=30^{\circ}\right)$ Eq. 2 pcs & $T_{24}[\mathrm{Nm}]$ & 0.07 & 0.07 \\
\hline$\left(\gamma=30^{\circ}\right)$ Uneq. 2 pcs & $T_{24}[\mathrm{Nm}]$ & 0.07 & 0.07 \\
\hline$\left(\gamma=60^{\circ}\right)$ Eq. 2 pcs & $T_{24}[\mathrm{Nm}]$ & 0.07 & 0.07 \\
\hline$\left(\gamma=60^{\circ}\right)$ Eq. 4 pcs & $T_{24}[\mathrm{Nm}]$ & 0.07 & 0.07 \\
\hline$\left(\gamma=60^{\circ}\right)$ Eq. 8 pcs & $T_{24}[\mathrm{Nm}]$ & 0 & 0 \\
\hline$\left(\gamma=60^{\circ}\right)$ Uneq. 8 pcs & $T_{24}[\mathrm{Nm}]$ & 0 & 0 \\
\hline
\end{tabular}

In Fig. 8 it can be seen that implementation of only unequal teeth widths can eliminate the $6^{\text {th }}$ torque ripple harmonic at the nominal load $\left(\gamma=0^{\circ}\right.$, Uneq., $\left.1 \mathrm{pc}\right)$ compared to the original design $\left(\gamma=0^{\circ}\right.$, Eq., 1 pc). Also, it is possible to eliminate $12^{\text {th }}$ and $24^{\text {th }}$ torque ripple harmonics by using skewing $\left(\gamma=30^{\circ}\right.$, Eq., 2 pcs $),\left(\gamma=30^{\circ}\right.$, Uneq., 2 pcs $),\left(\gamma=60^{\circ}\right.$, Eq., 4 pcs $)$, $\left(\gamma=60^{\circ}\right.$, Uneq., 4 pcs $),\left(\gamma=60^{\circ}\right.$, Eq., 8 pcs $),\left(\gamma=60^{\circ}\right.$, Uneq., 8 pcs). However, as it is seen in Fig. 8 , the skewing does not eliminate the $6^{\text {th }}$ torque ripple harmonic. The situation was similar to the one described in [18]. It is possible to achieve a reduction of the $6^{\text {th }}$ torque ripple harmonic, if the permanent magnets are divided on more than 2 parts during the skewing $\left(\gamma=60^{\circ}\right.$, Eq., 4 pcs $),\left(\gamma=60^{\circ}\right.$, Eq., 8 pcs $),\left(\gamma=60^{\circ}\right.$, Uneq., 8 pcs), but the total elimination of this harmonic is not possible if only skewing is implemented. The reason of this is the fact that skewing divides the machine in axial direction on several parts, where each part has different interaction of the armature flux with permanent magnet flux, due to different phase shifts of the fluxes created by the armature current linkage and permanent magnets along the axial direction. As it is shown above, this is the main reason of the unequal
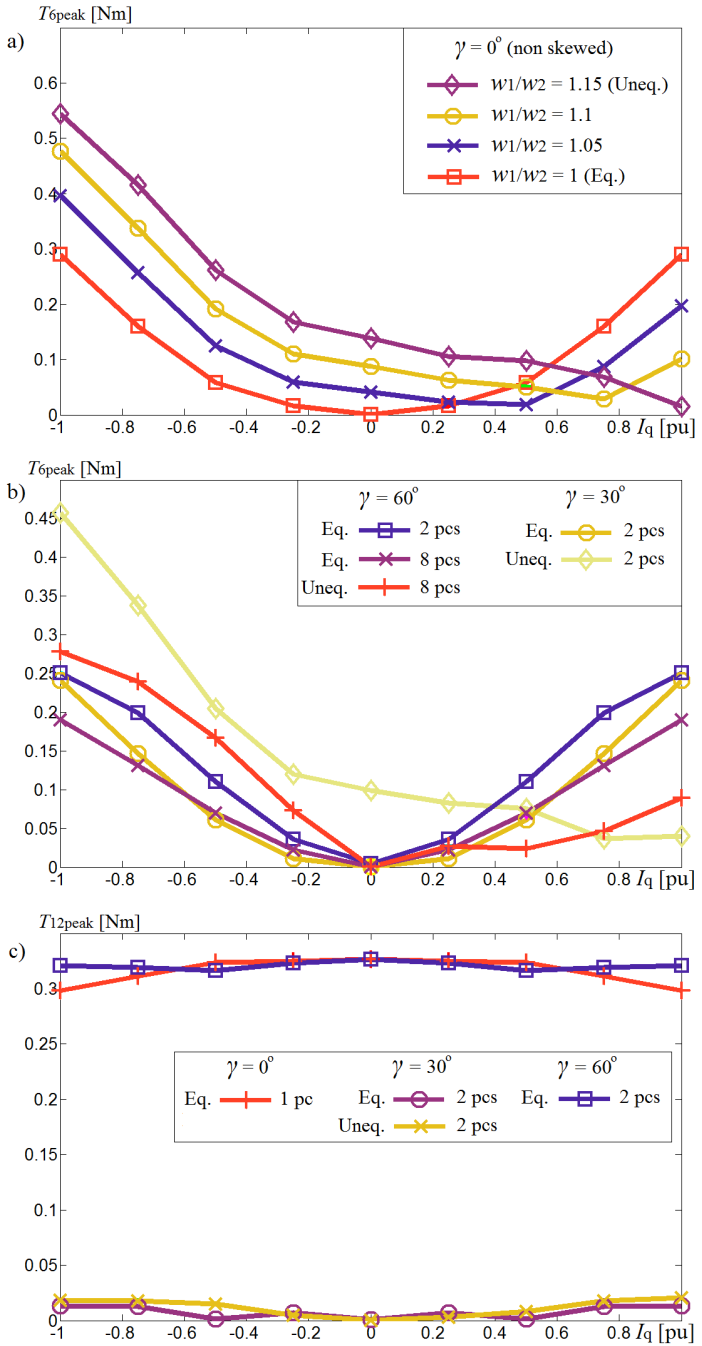

Fig. 10. Amplitude of a) the $6^{\text {th }}$ torque ripple harmonic at different ratios of the teeth widths $\left(w_{1} / w_{2}\right)$ without skewing $\left(\gamma=0^{\circ}\right)$ as function of the load, b) the $6^{\text {th }}$ torque ripple harmonic at different ratios of the teeth widths $\left(w_{1} / w_{2}\right)$ with skewing $\left(\gamma=30^{\circ}, \gamma=60^{\circ}\right)$ as function of the load, c) the $12^{\text {th }}$ torque ripple harmonic at different ratios of the teeth widths $\left(w_{1} / w_{2}\right)$ with and without skewing as function of the load, evaluated by FEA. When the $I_{\mathrm{q}}$ has negative value, the motor switches to the generator mode but rotates in the same direction.

maximum saturation levels in the stator teeth (1), (2). In other words, there is different saturation level in the stator teeth in the axial direction, if the skewing is implemented. Therefore, it is suggested that if the $6^{\text {th }}$ torque ripple harmonic should be eliminated or significantly reduced, the technique with unequal teeth widths described in the paper should be implemented without skewing $\left(\gamma=0^{\circ}\right.$, Uneq., 1 pc). However, in this case other torque ripple harmonics retain their presence.

The no-load cogging torque curves for different PMSM design solutions are illustrated in Fig. 9. The cogging torque can be eliminated by using skewing technique, without any additional approaches, due to the fact that there is no armature reaction at no-load [18]. In Fig. 9 and in Table I it can be seen that a particular cogging torque harmonic is eliminated if the angle (in electrical degrees), which takes half of the period of 

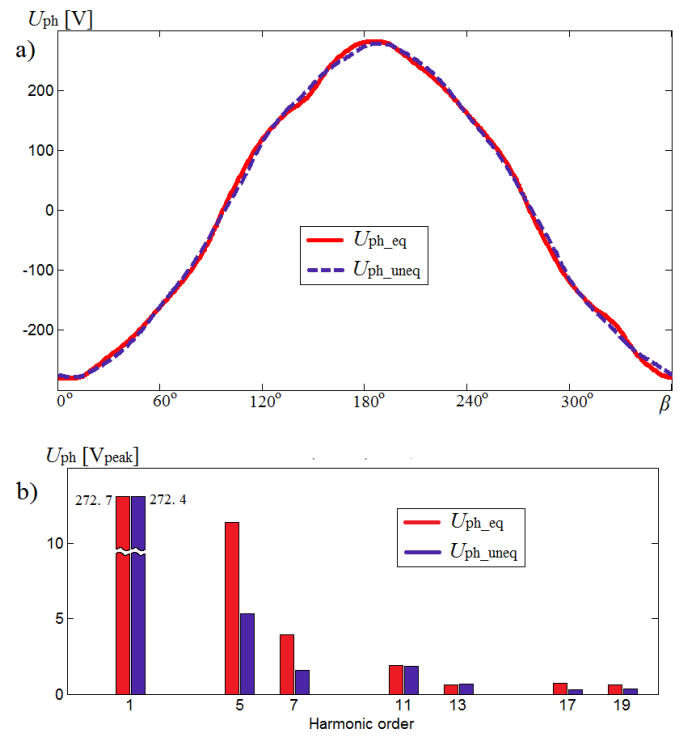

Fig. 11. a) Voltage at the terminals of the phase current supply of the original machine (with equal teeth widths) and of the redesigned machine (with unequal teeth widths) b) spectrum analysis of the voltages.

this harmonic is divided by angle $(\alpha)$ between two adjusted permanent magnets of the skewing (see Fig. 3) gives integer value. For example if the $12^{\text {th }}$ cogging torque harmonic is needed to be eliminated, the permanent magnets should be divided in the axial direction so that the angle between two adjacent permanent magnets is 15 electrical degrees, Fig. 3 (b) and (d), because half of the $12^{\text {th }}$ cogging torque harmonic takes $180 / 12=15$ electrical degrees.

The limitation of using the unequal teeth widths approach comes from the fact that, if the teeth widths are optimized, in order to have approximately equal flux density peaks in the stator teeth at one working point, they are not the same at other loads, because in this case the armature reaction (flux created by the armature current linkage) is different. It means that the $6^{\text {th }}$ harmonic order of the torque ripple is not completely eliminated at other working points, as it is illustrated in Fig. 10 (a). Therefore, the stator teeth widths optimization should be implemented with the knowledge of the prevailing loads. It is also shown that with negative torque (when $I_{\mathrm{q}}$ is negative) the torque ripple increases to the same extent as with positive torque in case of equal teeth widths, but with higher extent with the unequal stator teeth widths, due to the same reason (different armature reactions).

In Fig. 10 (b) it is seen that skewing does not significantly change the $6^{\text {th }}$ torque order harmonic in the PMSM with equal teeth widths. However, skewing can significantly reduce this harmonic at smaller loads with unequal teeth widths in the case of $\left(\gamma=60^{\circ}\right.$, Uneq., $\left.8 \mathrm{pc}\right)$, which makes this approach more practical, because in this case other torque ripple harmonics can be eliminated as well. The only disadvantage of using together skewing and unequal teeth widths approaches, as described above, is the fact that in this case at high loads the $6^{\text {th }}$ order harmonic is somehow higher, compared to using
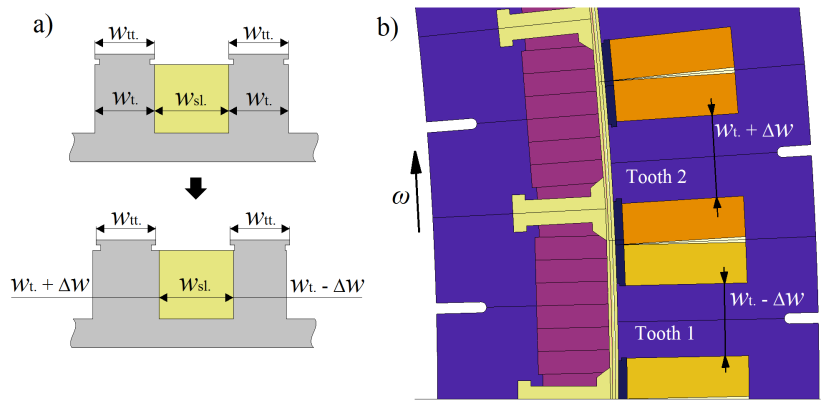

Fig. 12. Stator geometry optimization of 144-slot 120-pole TCW PMSM for the torque ripple reduction at the nominal load, a) principle of the stator teeth width adjustment, b) resultant geometry of the TCW PMSM. $w_{\mathrm{tt}}$. is the tooth tip width, which should be kept unchanged.

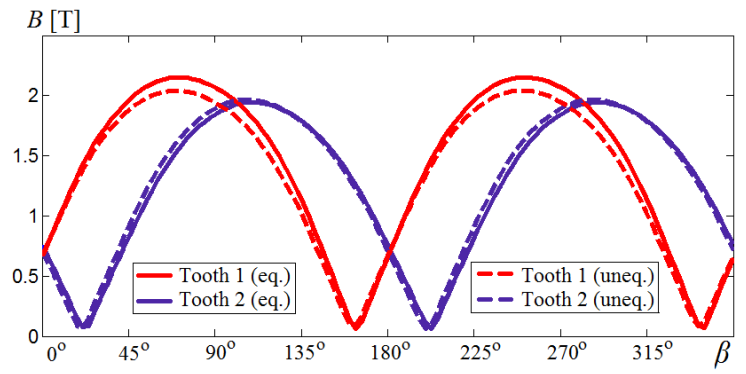

Fig. 13. Flux densities in the stator teeth of the original 144-slot 120-pole PMSM (with equal teeth widths) and those of the redesigned PMSM (with unequal teeth widths) at the nominal load.

unequal teeth widths alone, Fig. 10 (a), (b).

In Fig. 10 (c) it can be noticed that skewing almost eliminates the $12^{\text {th }}$ torque ripple harmonic, which is not significantly dependent on the load level. Therefore, it can be assumed that the $12^{\text {th }}$ harmonic and other higher order harmonics are only components of the cogging torque which indeed are easily eliminated by a proper skewing.

Some torque waveforms for different PMSM geometry solutions are not shown in Fig. 9, because they are near to fully coincide with other (shown) torque waveforms. For example, ( $\gamma=30^{\circ}$, Eq., 2 pcs $)$ at no-load has the same cogging torque behavior as $\left(\gamma=60^{\circ}\right.$, Eq., 4 pcs $)$, and $\left(\gamma=60^{\circ}\right.$, Uneq., 8 pcs) does not have any practical cogging torque as well as $\left(\gamma=60^{\circ}\right.$, Eq., 8 pcs $)$. However, all the simulated torque harmonic components for different design solutions can be found in Table I.

It should be noted that the described 12-slot 10-pole PMSM was analyzed with current supply. Therefore, the purely sinusoidal current was conducting in the stator windings. In this case the local saturations, which causes synchronous inductance variation, should influence the voltage waveform of the current supply. In Fig. 11 it can be seen that the voltage waveform of the current supply with unequal teeth widths is less interfered by high order harmonics compared to the original design.

Fig. 12 shows the geometry of a 144-slot 120-pole PMSM, which was designed for a direct drive wind generator [23]. 


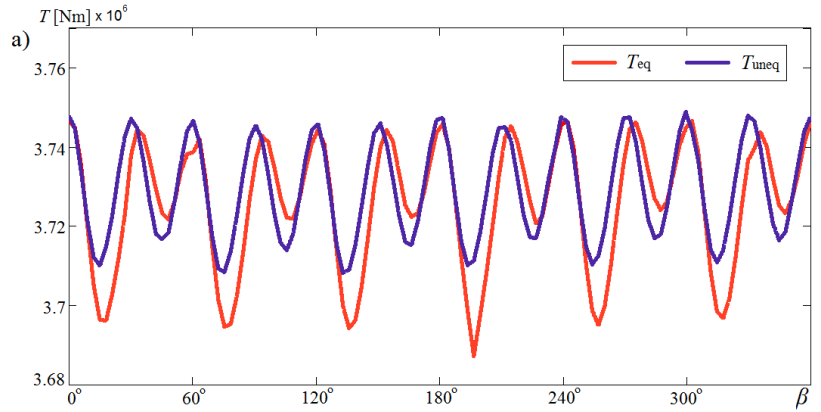

b)

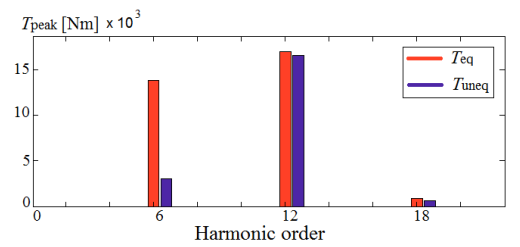

Fig. 14. a) Torque curves of the original 144-slot 120-pole PMSM (with equal teeth widths) and of the redesigned PMSM (with unequal teeth widths) at the nominal load and b) torque ripples harmonic spectrum. In both cases the voltage supply is used with the similar amplitude.
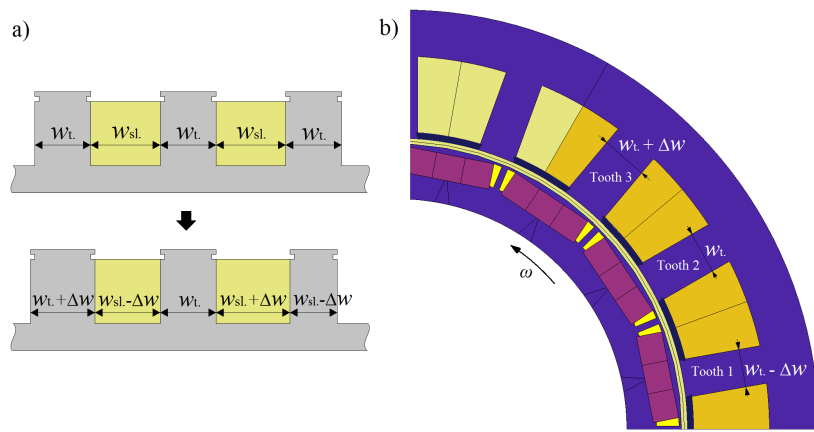

Fig. 15. Stator geometry optimization of a 18-slot 16-pole TCW PMSM for torque ripple reduction at the nominal load, a) principle of the stator teeth width adjustment, b) resultant geometry of the TCW PMSM.

One of the main design challenges of the PMSMs for this type of application is the reduction of the lowest harmonic components of the torque ripples, because otherwise it can degrade the performance of the whole system [22]. The stator teeth widths optimization of this electric machine was implemented in the same way as for 12-slot 10-pole PMSM (until the peak flux densities in the teeth have approximately the same values) as it is shown in Fig. 13. The resultant torque curves of the original PMSM (with equal teeth) and of the optimized PMSM (with unequal teeth) are shown in Fig. 14.

In Fig. 14 it can be seen that the $6^{\text {th }}$ harmonic order of the torque ripple was significantly reduced compared with the torque curve of the original PMSM. However, as it is noted above, at lower load conditions the $6^{\text {th }}$ harmonic order of the torque ripple increases, wehereas in the original design it reduces at lower torque. Therefore, the stator teeth widths should be selected according to the predicted load.

During the analysis of the original and redesigned wind generators the voltage sources were used. However, the saturation

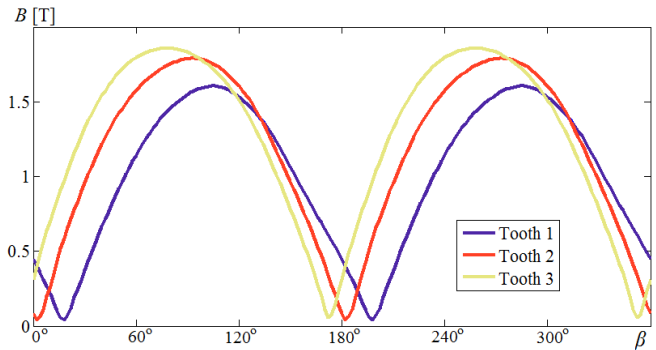

Fig. 16. Flux densities in three adjacent stator teeth of the original 18-slot 16-pole PMSM (with equal teeth widths) at the nominal load.

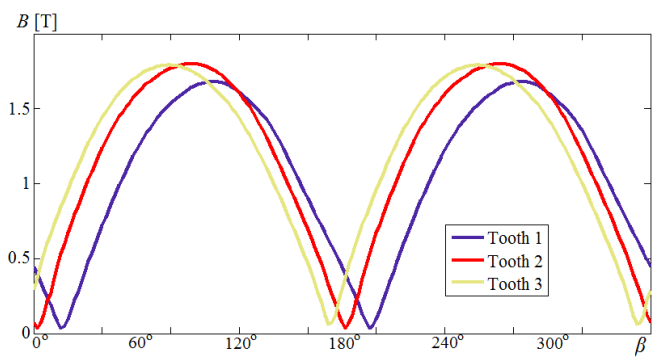

Fig. 17. Flux densities in the three adjacent stator teeth of the redesigned 18-slot 16-pole PMSM (with unequal teeth widths) at the nominal load.

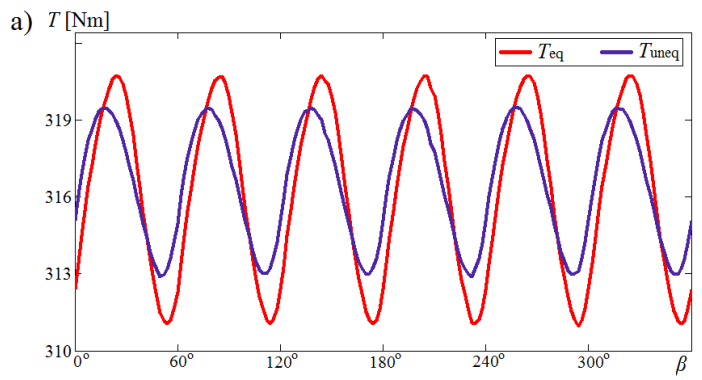

b)

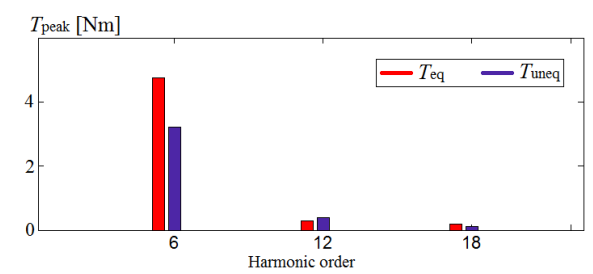

Fig. 18. a) Torque curves of the original 18-slot 16-pole PMSM (with equal teeth widths) and of the redesigned PMSM (with unequal teeth widths) at the nominal load and b) torque ripples harmonic spectrum.

in the stator teeth varies at different teeth widths, which leads to the synchronous inductance variation and consequently to the load angle change for the same working point. For example, in order to keep the same torque as of the original PMSM, the load angle $\delta$ of the redesigned wind generator was reduced from 52 to 50 electrical degrees. It means that the generator with enequal stator teeth has approximately $3 \%$ higher overload capability than the original design.

It should be noted that the described optimization method should suit not only for TCW PMSMs with $q=0.4$ and with rotor surface permanent magnets, but also for PMSMs 
with other numbers of slots per pole and phase as well as with rotor embedded magnets. As an example a TCW PMSM with 18-slot 16-pole was analyzed [24]. Fig. 15 shows the geometry of this TCW PMSM. The major difference between this electric machine $(q=0.375)$ and the above described PMSMs $(q=0.4)$ is the fact that there are three adjacent stator teeth with different peak flux densities at the nominal load, as it is illustrated in Fig. 16. In order to reduce the torque ripple, the stator teeth widths were adjusted accordingly to the above described procedure, and the resultant flux densities at the nominal load are shown in Fig. 17. The torque curves of the original PMSM and of the optimized one are shown in Fig. 18. One significant drawback, when three teeth widths are adjusted, is the fact that the stator slots have different widths (areas), and other approaches are needed in order to make the slot areas equal (e.g. alternate the stator yoke widths in each slot).

In Fig. 18 it is seen that the $6^{\text {th }}$ harmonic order of the torque ripple was reduced, but not so significantly as in the previous electric machines (with rotor surface permanent magnets). It can be explained by the presence of the rotor steel near to the air gap, which can also have a strong local saturation.

\section{CONCLUSION}

The reasons of local saturation in the stator side of TCW PMSMs are described. It is shown that these saturations, which cause asymmetrical permeability variations in the magnetic circuit, can produce some high order harmonics in the PMSM torque.

Possible design solutions are suggested and verified by finite element analysis, for the elimination of these effects and for reducing the torque ripple.

It was found that in TCW PMSMs, the $6^{\text {th }}$ torque ripple harmonic is partially produced by non-symmetrical peak flux density distributions in the stator teeth, due to interaction of the permanent magnet flux with armature flux. The $6^{\text {th }}$ harmonic can be eliminated by teeth widths adjustment, whereas conventional skewing technique is not appropriate for the reduction of this harmonic. However, skewing is still favorable for the elimination of cogging torque in TCW PMSMs. The main disadvantage of the method with unequal stator teeth is that it gives the desirable results for only one working point, whereas for other loads the $6^{\text {th }}$ torque ripple harmonic increases.

The described methods can be used by designers, which should be aware of these local saturations in TCW PMSMs, especially when low torque ripple is one of the design targets.

\section{REFERENCES}

[1] H. Jussila, "Concentrated winding multiphase permanent magnet machine design and electromagnetic properties - case axial flux machine," Ph.D dissertation, Dept.Elect.Eng., Lappeenranta University of Technology, 2009.

[2] A. EL-Refaie, "Fractional-slot concentrated-windings synchronous permanent magnet machines: Opportunities and challenges," Industrial Electronics, IEEE Transactions on, vol. 57, no. 1, pp. 107-121, 2010.

[3] R. Dutta, M. F. Rahman, and L. Chong, "Winding inductances of an interior permanent magnet (ipm) machine with fractional slot concentrated winding," Magnetics, IEEE Transactions on, vol. 48, no. 12, pp. 4842-4849, 2012.
[4] T. D. Strous, H. Polinder, and J. Ferreira, "Inductance calculations for pm machines with concentrated windings," in Electric Machines Drives Conference (IEMDC), 2011 IEEE International, 2011, pp. 447-452.

[5] L. Alberti and N. Bianchi, "Theory and design of fractional-slot multilayer windings," Industry Applications, IEEE Transactions on, vol. 49, no. 2, pp. 841-849, 2013.

[6] M. Cistelecan, F. Ferreira, and M. Popescu, "Three phase toothconcentrated multiple-layer fractional windings with low space harmonic content," in Energy Conversion Congress and Exposition (ECCE), 2010 IEEE, 2010, pp. 1399-1405.

[7] M. Barcaro and N. Bianchi, "Torque ripple reduction in fractionalslot interior pm machines optimizing the flux-barrier geometries," in Electrical Machines (ICEM), 2012 XXth International Conference on, 2012, pp. 1496-1502.

[8] I. Petrov and J. Pyrhonen, "Performance of low-cost permanent magnet material in pm synchronous machines," Industrial Electronics, IEEE Transactions on, vol. 60, no. 6, pp. 2131-2138, 2013.

[9] P. Ponomarev, "Tooth-coil permanent magnet synchronous machine design for special applications," Ph.D dissertation, Dept.Elect.Eng., Lappeenranta University of Technology, 2013.

[10] P. Sergeant and A. Van den Bossche, "Influence of the amount of permanent-magnet material in fractional-slot permanent-magnet synchronous machines," Industrial Electronics, IEEE Transactions on, vol. 61, no. 9, pp. 4979-4989, Sept 2014.

[11] G. Sizov, P. Zhang, D. Ionel, N. Demerdash, and M. Rosu, "Automated multi-objective design optimization of pm ac machines using computationally efficient fea and differential evolution," Industry Applications, IEEE Transactions on, vol. 49, no. 5, pp. 2086-2096, Sept 2013.

[12] J. Pyrhönen, T. Jokinen, and V. Hrabovcová, Design of Rotating Electrical Machines. New York: John Wiley Sons, 2008.

[13] P. Ponomarev, J. Alexandrova, I. Petrov, P. Lindh, E. Lomonova, and J. Pyrhonen, "Inductance calculation of tooth-coil permanent-magnet synchronous machines," Industrial Electronics, IEEE Transactions on, vol. PP, no. 99, pp. 1-8, 2014.

[14] A. El-Refaie, Z. Zhu, T. Jahns, and D. Howe, "Winding inductances of fractional slot surface-mounted permanent magnet brushless machines," in Industry Applications Society Annual Meeting, 2008. IAS '08. IEEE, 2008, pp. 1-8.

[15] J. Montonen, P. Lindh, and J. Pyrhonen, "Design process of traction motor having tooth coil windings," in Electrical Machines (ICEM), 2012 XXth International Conference on, 2012, pp. 1264-1268.

[16] L. Alberti, M. Barcaro, and N. Bianchi, "Design of a low torque ripple fractional-slot interior permanent magnet motor," in Energy Conversion Congress and Exposition (ECCE), 2012 IEEE, 2012, pp. 509-516.

[17] K. Wang, Z. Zhu, and G. Ombach, "Torque enhancement of surfacemounted permanent magnet machine using third-order harmonic," Magnetics, IEEE Transactions on, vol. 50, no. 3, pp. 104-113, March 2014.

[18] W. Chu and Z. Zhu, "Investigation of torque ripples in permanent magnet synchronous machines with skewing," Magnetics, IEEE Transactions on, vol. 49, no. 3, pp. 1211-1220, March 2013.

[19] P. Ponomarev, I. Petrov, and J. Pyrhonen, "Influence of travelling current linkage harmonics on inductance variation, torque ripple and sensorless capability of tooth-coil permanent-magnet synchronous machines," Magnetics, IEEE Transactions on, vol. 50, no. 1, pp. 1-8, Jan 2014.

[20] D. Ishak, Z. Zhu, and D. Howe, "Permanent-magnet brushless machines with unequal tooth widths and similar slot and pole numbers," Industry Applications, IEEE Transactions on, vol. 41, no. 2, pp. 584-590, 2005.

[21] 2014. [Online]. Available: http://www.sura.se

[22] J. Sopanen, V. Ruuskanen, J. Nerg, and J. Pyrhonen, "Dynamic torque analysis of a wind turbine drive train including a direct-driven permanent-magnet generator," Industrial Electronics, IEEE Transactions on, vol. 58, no. 9, pp. 3859-3867, 2011.

[23] Y. Alexandrova, R. Semken, and J. Pyrhnen, "Permanent magnet synchronous generator design solution for large direct-drive wind turbines," International Review of Electrical Engineering (IREE), vol. 8, no. 6, 2013.

[24] P. Ponomarev, P. Lindh, and J. Pyrhonen, "Effect of slot-and-pole combination on the leakage inductance and the performance of toothcoil permanent-magnet synchronous machines," Industrial Electronics, IEEE Transactions on, vol. 60, no. 10, pp. 4310-4317, 2013.

[25] J. Krotsch, T. Ley, and B. Piepenbreier, "Reduction of torque and radial force fluctuation in permanent magnet synchronous motors by means of multi-objective optimization," in Electric Drives Production Conference (EDPC), 2011 1st International, Sept 2011, pp. 40-48. 